\title{
Oral health — educating mothers with young children
}

\author{
Effectiveness on oral health of a long-term health education programme for mothers with young children \\ M. B. Kowash, A. Pinfield, J. Smith, and M. E. J. Curzon BrDent J 2000; 188: 201-205
}

\section{Aim}

To determine the effect of dental health education (DHE) on caries incidence in infants, through regular home visits by trained DH Educators over a period of 3 years.

\begin{abstract}
Method
A randomly selected cohort of 228 children born between 1 st January and 30th September 1995, in a low socio-economic/high caries suburb of Leeds (UK) were divided into the following groups: A) DHE focused on diet; B) DHE focused on oral hygiene instruction (OHI) using fluoride toothpaste; and C) DHE by a combined diet and $\mathrm{OHI}$ message. DHE was given using an interview and counselling for at least 15 minutes at home every 3 months for the first 2 years and twice a year in the third year of the study. A fourth group D was given diet and OHI, at home, once a year only. All children and mothers were examined for caries and oral hygiene. A fifth group E (control) received no DHE and were never visited but examined at 3 years of age only.

\section{Results}

In the groups of children visited regularly only two developed caries and three had gingivitis (all in group A). In group E, however, $33 \%$ of children had caries and nine $(16 \%)$ had gingivitis. The differences in caries levels and caries risk factors between study and control groups were statistically significant $(P<0.001)$. Mothers of the study groups also showed an improvement in their own levels of gingivitis, debris and calculus scores by the second and third examinations $(P<0.001)$.
\end{abstract}

\section{Conclusion}

Regular home visits to mothers with infants, commencing at or soon after the time of the eruption of the first deciduous teeth, was shown to be effective in preventing the occurrence of nursing caries.

\section{In brief}

- Nursing caries (NC) is still a continuing problem, especially in children from lower social class, migrants and ethnic minority populations.

- In addition to the well-known four aetiological factors of dental caries, poor parenting may be an important factor in NC.

- Dental health education (DHE) as a preventive strategy for $\mathrm{NC}$ is rarely studied and evaluated in a randomised way.

- The main benefit from this study was that repeated visits to provide DHE to mothers of infants in their homes was very successful in preventing NC.

- Another finding of note was the improvement in maternal gingival and oral hygiene status.

- Finally, the two dental health educators were a dental hygienist and an outreach paediatric nursing sister. The implication here is that dentally aware midwifes and health visitors could be as effective as dental personnel.

\section{Comment}

$\mathrm{T}^{\mathrm{t}}$ seems only yesterday that the discipline 1 of oral health promotion was embroiled in an uninformative 'yes, it works' 'no, it doesn't work' debate. Fortunately, however, the discussion has moved on to a more sophisticated level, assisted for example by Daly and Watt ${ }^{1}$ and Watt and Fuller. ${ }^{2}$ As a recent conference on evidence-based dentistry convened by Dr Derek Richards demonstrated, oral health promotion is now firmly part of the wider movement towards evidence-based practice in medicine and dentistry. Some considerations are particular to health promotion, such as the limitations of using randomised controlled trials (RCTs) to assess the full range of processes and outcomes involved in many interventions, but other issues relating to raising quality standards and changing ingrained professional practices remain common.

This paper is a welcome addition to the published literature on dental health education, because systematic reviews are only as good as the basic research underpinning them, and previous reviews have unanimously pointed out the paucity of good quality studies in this field..$^{3,4}$ In particular, it is valuable that this paper describes an intervention which has been planned and sustained over a period of years. Too often, short-term one-off interventions achieve very limited results, and this taints the efforts of all those involved in health education/promotion.

Additionally, there are clinically measurable outcomes reported in the paper - often in health education/promotion, clinical outcomes are either difficult to measure within the timeframe of the project, or the differences noted cannot be ascribed with confidence to the intervention. This can throw doubt on whether dental health education can do any more than simply alter knowledge. Finally it is often suggested that early interventions may yield better results than waiting until an individual's or family's problems and 'unhealthy behaviours' are well entrenched. This paper helpfully adds to the thin literature looking at interventions aimed at very young children and their parents, and includes a reference to costeffectiveness - an important aspect of interventions which is often glossed over.
I hope this paper will be followed by others of publishable quality, describing interventions using the full range of strategies set out in the Ottawa Charter: practical, evidence-based guidance for those wishing to plan and implement effective health promotion interventions has been provided recently by Watt. ${ }^{5}$

\section{Catherine Stillman-Lowe}

Oral Health Programme Manager, Health Education Authority

1 Daly B, Watt R G. Designing and evaluating effective oral health promotion. Oral Health Promotion Research Group 1998.

2 Watt R G, Fuller S S. Oral health promotion opportunity knocks! Br Dent J 1999; 186: 3-6.

3 Sprod A, Anderson R, Treasure E T. Effective oral health promotion. Literature Review. Health Promotion Wales. Technical Report 20 1996.

4 Kay E J, Locker D. Effectiveness of Oral Health Promotion: a review. Health Education Authority 1997.

5 Watt R (ed). Oral Health Promotion: a guide to effective working in pre-school settings. Health Education Authority 1999. 